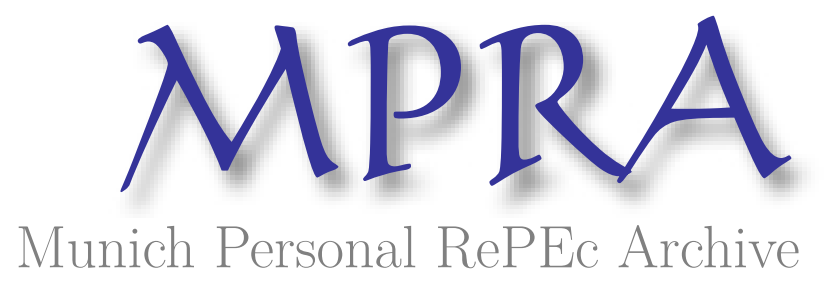

\title{
On The Term Structure of South African Interest Rates: Cointegration and Threshold Adjustment
}

Njindan Iyke, Bernard

1 April 2015

Online at https://mpra.ub.uni-muenchen.de/67681/

MPRA Paper No. 67681, posted 06 Nov 2015 15:29 UTC 


\title{
On The Term Structure of South African Interest Rates: Cointegration and Threshold Adjustment
}

\author{
By
}

\author{
Bernard Njindan Iyke ${ }^{1}$ \\ Department of Economics \\ University of South Africa \\ P.O. Box 392, UNISA \\ 0003, Pretoria \\ South Africa
}

Email: niykeb@unisa.ac.za / benitoflex@gmail.com

\section{April 2015}

${ }^{1}$ Corresponding Author [Research Fellow, Economics Department, University of South Africa, Pretoria] 


\title{
On The Term Structure of South African Interest Rates: Cointegration and Threshold Adjustment
}

\begin{abstract}
This paper explores the correlations of the short- and long-term interest rate series through time in South Africa. Two time series techniques are utilized: the Kapetanios et al. (2003) nonlinear STAR unit root test and the asymmetric cointegration with threshold adjustment test of Enders and Siklos (2001). We find the interest rate series (i.e. the SARB policy rate and the yield on long-term government bonds) to be cointegrated with fairly weak threshold adjustment. In addition, we find a distinct causal flow from the yield on long-term government bonds to the $S A R B$ policy rate with momentum equilibrium adjustment symmetry, indicating that linear error correction models may fit the yield curves in South Africa better.
\end{abstract}

Keywords: Asymmetric Adjustment, Cointegration, Term Structure, Interest Rates, South Africa JEL Classification: C22, E43 


\section{Introduction}

Most empirical studies proceed to examine the relationships between macroeconomic variables on the basis that such relationships are linear. However, some classic studies have found key macroeconomic variables such as interest rates, real gross domestic product, and unemployment to exhibit nonlinear adjustment over the business cycle (see Enders and Siklos, 2001). This means to assume that macroeconomic variables relate to each other in a linear fashion can be very misleading. Granger and Lee (1989), for example, find sales, production, and inventories in the US to rather adjust asymmetrically to equilibrium, contrary to what previous studies document. Balke and Fomby (1997) find short-term and long-term interest rates to correlate asymmetrically towards equilibrium. Thus, care must be taken when examining the links between macroeconomic variables, since inappropriate findings can prove to have far-reaching policy consequences.

Different studies explore various aspects of the term structure of interest rates in the literature. For example, Kessel (1965) finds co-movements of the term structure and the business cycle. He finds the size of the yield spread to correlate strongly with general economic conditions such as expansions and recessions. Bernanke (1983) finds the spread between the rate on BAA-rated corporate bonds and treasury bonds to lead output growth during the inter-war period. Stock and Watson (1989) find two interest rate spreads (i.e. the difference between six-month commercial paper rate and six-month treasury bill rate, and the difference between ten-year and one-year treasury bonds rates) to offer better forecasts of business cycles than other variables. Studies such as Bernanke and Blinder (1989), Friedman and Kuttner (1989), Harvey (1989), Bernanke (1990), Chen (1991), and Estrella and Hardouvelis (1991) emphasize the forecasting power of term structure of interest rates for predicting real economic activities. McCallum (1994) and 
Rudebusch (1995) examine the forecasting content of long-short spread for future movements in the interest rates. Fuhrer and Moore (1995), and Fuhrer (1996) explore the interaction between the term structure and shifts in the conduct of monetary policy in vector autoregressive models. Others, such as McGough et al. (2005), Tesfaselassie et al. (2006) consider the indeterminacy of rational expectations equilibra within New Keynesian models. Meanwhile, Joyce et al. (2009) investigates the nature of nominal and real interest rate term structures during inflation-targeting regimes. Schaling et al. (2009) analyze the implications of the expectation theory of the term structure of interest rates for the implementation of inflation targeting.

On the co-movements of interest-rate series, some key interesting country-specific studies document important conclusions. MacDonald and Speight (1988), McFadyen et al. (1991), Hall et al. (1992), Wallace and Warner (1993), and Mandeno and Giles (1995) find strong evidence of long-run co-movements of interest-rate series. In their influential paper, Enders and Siklos (2001) find strong cointegrating relationship between short- and long-term interest rates. They argue that cointegration is evident when momentum threshold auto-regression adjustments are allowed; and that cointegration dissipates under linear cointegration models. Studies such as Mustafa and Rahman (1995), and Taylor (1992) do not find any relationships between interestrate series, however.

In the South African context, representative studies such as Nel (1996) examine the correlations between the term structure of interest rates and the growth in real economic activity. He finds the slope of the yield curve to correlate positively to real growth of GDP in South Africa. Arize et al. (2002) investigate the long-run co-movements of short-term and long-term interest-rate series for nineteen countries including South Africa. These authors find short- and long-term interest rates to move together in the long run. Moolman (2002) employs forward rates as proxies for interest 
rate expectations to verify whether market participants can predict accurately the Reserve Bank's decisions on repo rates before Monetary Policy Committee (MPC) meetings. He finds changes in market interest rates to occur prior to the day of repo rate changes. In addition, Khomo and Aziakpono (2007) examine the predictive power of the yield curve relative to other indexes in predicting recessions. They find the yield curve to be a better predictor than the other indexes at longer horizons. In a recent paper, Dube and Zhou (2013) find evidence of threshold cointegration between short- and long-term interest rates in South Africa.

The evidence shows that Arize et al. (2002), and Dube and Zhou (2013) are the only studies which examine the co-movements of interest rate series for South Africa, to the best of our knowledge. The first authors assume that the cointegrating adjustment mechanism is symmetric. This assumption, as discussed earlier, has been found to be invalid for time series such as interest rates. This means that the conclusions put forth by these authors can be misleading. Dube and Zhou (2013) resolve this problem by fitting a two-regime vector error correction model for the term structure of interest rates in South Africa using the Hansen-Seo algorithm. Our paper adds to the literature by using nonlinear models which are different from the ones utilized in Dube and Zhou (2013) to examine the dynamic correlations between short-term and long-term interest rates in South Africa. The importance of dynamic interest rate correlations is summed up by how such correlations act as leading indicators for business cycle predictions. As is well-noted, inverted yield curves are early warnings of recessions (see Estrella and Mishkin, 1997). Yield curves may also serve as better indicators of monetary policy than growth rates of money (see McCallum, 1983) - an argument re-enforced by Bernanke and Blinder (1989), and Piazzesi (2010). 
We proceed with our analysis in a stepwise fashion. First, we examine the stationary properties of the interest-rate series (namely, the SARB policy rate and the yield on long-term government bonds) using linear and nonlinear unit root tests. We find the two interest-rate series to be firstdifference stationary or I(1) processes under linear and non-linear unit root tests. Next, we test for cointegrating relationships between the interest-rate series using linear and nonlinear cointegration techniques. We find the evidence of cointegrating relationship between the two interest-rate series to be fairly strong, using the linear Johansen cointegration test. Similarly, we find evidence of cointegrating relationship between the interest-rate series using the nonlinear cointegration test of Enders and Siklos (2001). The nonlinear cointegration results indicate that positive deviations from the long-term equilibrium due to increases in the SARB policy rate or decreases in the yield on long-term government bonds are corrected at $2.6 \%$ per month. Negative deviations from the long-term equilibrium due to decreases in the SARB policy rate or increases in the yield on long-term government bonds are corrected at $6 \%$ per month. Since the interestrate series are cointegrated with threshold adjustment, we estimate the corresponding nonlinear error correction model. The results indicate that there is a distinct causal flow from the long-term government bonds yield to the SARB policy rate. There is, however, no momentum equilibrium adjustment asymmetry, indicating that the nonlinear error correction model may not fit the term structure of interest rates in South Africa well. This finding is in stark contrast to the finding presented in Dube and Zhou (2013). On this account, we fit a linear error correction model and find short- and long-run causal flow from the yield on long-term government bonds to the SARB policy rate. The dependence of the SARB policy rate on the long-term government bonds yield is consistent with the monetary policy framework pursued by the Reserve Bank of South Africa (the SARB). Nel (1996) notes that the SARB's monetary policy controls are focused on short- 
term interest rates, whereas long-term interest rates are influenced by market forces (see SARB Fact sheets, 2007).

The remaining sections of this paper are organized as follows: in the next section we discuss our methodology and the data. Then, in section 3, we present and discuss our results. In the final section, we present the concluding remarks.

\section{Methodology}

\subsection{Linear Unit Root Tests}

As a preliminary analysis, prior to examining the nature of the relationship between the two interest-rate series, we examine their stationary properties. We utilize the Dickey-Fuller Generalized Least Squares (DF-GLS) and the Ng-Perron tests, proposed by Elliot et al. (1996), and $\mathrm{Ng}$ and Perron (2001), respectively. The motivation for using these unit root tests is that the canonical tests for stationarity (such as the ADF and PP tests) are found to frequently reject the null hypothesis of unit root, when the time series under consideration has a large and negative moving average (MA) component, even when there is a unit root (see Schwert, 1986; Caner and Killian, 2001). Elliot et al. (1996), and $\mathrm{Ng}$ and Perron (2001) demonstrate, respectively, that the DF-GLS and the Ng-Perron tests have substantially higher power, even when the root of the time series is closer to unity. In order to estimate results which are based on parsimonious regressions, we determine the optimal lags for both tests using the Modified Akaike Information Criterion (MAIC). The regressions and test statistics underlying these unit roots techniques have been well-discussed in various studies. So we do not present them here, in order to optimize space. 


\subsection{Nonlinear Unit Root Test}

The unit root tests described above are developed on the notion that the mean-reverting properties of the variable under consideration follow a linear process. However, if the characteristic mean-reverting process exhibits nonlinearities, then these unit roots tests will frequently fail to reject the null hypothesis of unit root (see Kapetanios et al., 2003). Indeed, this has often been the case in specific areas of economics such as international monetary economics where the real exchange rate in particular has been found to be non-stationary (see Taylor et al., 2001), and international finance which documents evidence on the unit root behaviour of the real interest rate (see Rose, 1988).

Kapetanios et al. (2003) propose a novel unit root test which attempts to capture the supposed nonlinear behaviour in the data-generating process of time series variables. In this paper, we employ this nonlinear unit root test, since the variables we use are suspect of nonlinear movements. The Kapetanios-Shin-Snell (KSS) test detects the presence of unit root against a nonlinear globally stationary exponential smooth transition autoregressive (ESTAR) process of the form:

$$
\Delta y_{t}=\gamma y_{t-1}\left\{1-\exp \left(-\theta y_{t-1}^{2}\right)\right\}+\varepsilon_{t}
$$

where $\Delta$ is the first difference operator, $y_{t}$ is the time series variable being tested, $\gamma$ is a coefficient, $\theta \geq 0$ is the transition parameter of the ESTAR model, $t$ is the time period, and $\varepsilon_{t}$ is the white-noise error term.

The hypothesis of interest is stated such that $\theta=0$ implies $y_{t}$ is a non-stationary linear process against the alternative of $\theta>0$, which implies $y_{t}$ is a stationary nonlinear ESTAR process. $\gamma$ is said to be unidentified under the null hypothesis of linear unit root. Thus, Kapetanios et al. 
(2003) compute a first-order Taylor series approximation to the ESTAR model under the null hypothesis of $\theta=0$ and derive a $t$-type test statistic, following Luukkonen et al. (1988). Equation (1) becomes the following auxiliary regression:

$$
\Delta y_{t}=\delta y_{t-1}^{3}+\varepsilon_{t}
$$

With some extension to (1) for a general case of serially correlated errors, Kapetanios et al. (2003) arrive at the general auxiliary regression for (2) in the form:

$$
\Delta y_{t}=\sum_{j=1}^{p} \rho_{j} \Delta y_{t-1}+\delta y_{t-1}^{3}+\varepsilon_{t}
$$

where $p$ is the optimal lag to be included in the regression using AIC or BIC, and $\rho_{j}$ and $\delta$ are coefficients to be estimated. The hypotheses are then formulated such that $\delta=0$ implies unit root against $\delta<0$ implies nonlinear stationary ESTAR process. The $t$-type statistic obtain for $\delta$ (i.e. $t_{N L}=\hat{\delta} / \operatorname{se}(\hat{\delta})$ ) could then be compared to the simulated critical values for the three different cases tabulated by Kapetanios et al. (2003, Table 1, p. 364).

\subsection{Linear Cointegration Tests}

In this paper, we adopt two linear cointegration techniques: (i) the Johansen technique proposed by Johansen (1988), Johansen and Juselius (1990), and Johansen (1991 and 1995); and (ii) the Engle-Granger two-step technique developed by Engle and Granger (1987), to examine the existence of linear cointegrating relationship between the interest-rate series. The Johansen procedure is based on the following specifications:

$$
y_{t}=A_{1} y_{t-1}+\cdots+A_{p} y_{t-p}+B x_{t}+\varepsilon_{t}
$$


where $y_{t}$ is a $k$-vector non-stationary I(1) variables (i.e. SARB policy rate and yield on longterm government bonds, in this paper); $x_{t}$ is a $d$-vector of deterministic variables; and $\varepsilon_{t}$ is a vector of innovations or disturbances. Equation (1) could be formulated in the form:

$$
\Delta y_{t}=\Pi y_{t-1}+\sum_{i=1}^{p-1} \Gamma_{i} \Delta y_{t-i}+B x_{t}+\varepsilon_{t}
$$

where: $\Pi=\sum_{i=1}^{p} A_{i}-I$ and $\Gamma_{i}=\sum_{j=i+1}^{p} A_{i}$

According to the Engle-Granger representation theorem, if the coefficient matrix, П, has a reduced rank, $r<k$, then there exist $k \times r$ matrices $\alpha$ and $\beta$ each with rank $r$ such that $\Pi=\alpha \beta^{\prime}$ and $\beta^{\prime} y_{t}$ is stationary; where $r$ denotes the number of cointegration relations and $\beta$ denotes the cointegrating vector; $\alpha$ represents the adjustment parameters in the vector error-correction model. The Johansen procedure estimates the matrix, $\Pi$, from an unrestricted vector autoregressive model and tests whether the restrictions implied by the reduced rank of $\Pi$ could be rejected (see Johansen, 1995).

Johansen and Juselius (1990), and Johansen (1995) developed the trace test $\left(\lambda_{\text {trace }}\right)$ and the maximum eigenvalue test $\left(\lambda_{\max }\right)$ for doing this. Gonzalo and Pitarakis (1998), and Aznar and Salvador (2002) suggested that we could instead determine the number of cointegration relations by defining an estimator which minimizes an information criterion with known asymptotic properties. In this paper, we select the number of cointegrating relations that minimizes the Akaike Information Criterion (AIC), the Bayesian Information Criterion (BIC) or the Ljung-Box Q test. 
The Engle-Granger two-step technique relies heavily on the data-generating process of the residuals from the long-run relationship of time series (see Engle and Granger, 1987). The technique follows specifications of the form:

$$
\begin{aligned}
& y_{t}=\beta_{0}+\beta_{1} x_{t}+\mu_{t} \\
& \Delta \hat{\mu}_{t}=\psi \hat{\mu}_{t-1}+\sum_{i=1}^{k} \phi_{i} \Delta \hat{\mu}_{t-i}+\xi_{t}
\end{aligned}
$$

where $\beta_{0}, \beta_{1}, \psi$ and $\phi_{i}$ are coefficients to be estimated, $\mu_{t}$ is the error term, $\hat{\mu}_{t}$ is the estimated residual series, $\Delta$ is the first difference operator, $\xi_{t}$ is the white-noise error term, and $k$ is the number of lags to be determined by the AIC, BIC or Ljung-Box Q test. Note that the series assumed to be the driver of the long-run relationship is chosen as the dependent variable in (6). After (6) is estimated, $\hat{\mu}_{t}$ is then predicted in order to estimate (7). The final step is to examine the stationary properties of $\hat{\mu}_{t}$. The null hypothesis is conducted such that $\psi=0$ implies no cointegration between $y_{t}$ and $x_{t}$. A rejection of $\psi=0$ means that $y_{t}$ and $x_{t}$ are cointegrated (see Engle and Granger, 1987).

\subsection{Nonlinear Cointegration Test}

The Johansen and the Engle-Granger techniques for testing cointegration that we have described above assume that the time series are linearly related; and if the time series are cointegrated, these techniques assume that the adjustment mechanism towards equilibrium is symmetric. In reality, this may not always be the case. For example, Granger and Lee (1989) found that sales, production, and inventories in the U.S. exhibit asymmetric adjustment toward a long-run multicointegrating relationship (see Enders and Siklos, 2001). In addition, Siklos and Granger (1997) 
find the strength of the interest rate parity to evolve in the course of time, implying asymmetric adjustment to equilibrium.

Balke and Fomby (1997) argue that, in cases where researchers suspect that the series are nonlinearly related, a two-step technique for threshold cointegration should be used. On this basis, Enders and Granger (1998), and Enders and Siklos (2001) derive a generalized DickeyFuller test for the Engle-Granger two-step technique which captures possible nonlinear comovement of the series towards long-run equilibrium. Some recent studies have since applied this technique. The interested reader could find recent applications of the nonlinear cointegration technique we discuss here in Shen et al. (2007), Yau and Nieh (2009), and Sun (2011).

The nonlinear cointegration technique we employ in this paper is a two-regime threshold cointegration technique which was developed by Enders and Siklos (2001). It is a simple extension of the Engle-Granger two-step technique. Enders and Siklos (2001) modify (7) to account for nonlinear transmission mechanism in the form:

$\Delta \hat{\mu}_{t}=\psi_{1} I_{t} \hat{\mu}_{t-1}+\psi_{2}\left(1-I_{t}\right) \hat{\mu}_{t-1}+\sum_{i=1}^{q} \phi_{i} \Delta \hat{\mu}_{t-i}+\epsilon_{t}$

$I_{t}=1$ if $\hat{\mu}_{t-1} \geq \tau, 0$ otherwise

Or

$I_{t}=1$ if $\Delta \hat{\mu}_{t-1} \geq \tau, 0$ otherwise

where $I_{t}$ is the Heaviside indicator, $\psi_{1}, \psi_{2}$ and $\phi_{i}$ are the coefficients, $q$ is the number of lags, and $\tau$ is the threshold value. In order to determine $q$, which accounts for the order of autocorrelated residuals, Enders and Siklos (2001) propose we use the AIC, BIC, or Ljung-Box Q test. 
There are two ways in which the Heaviside indicator, $I_{t}$, could be specified. First, (8) and (9a) called the Threshold Autoregression (TAR) model; and second, (8) and (9b) called the Momentum Threshold Autoregression (MTAR) model. The TAR model takes into account potential nonlinear "deep" movements in the residual; whereas the MTAR model accounts for potential "steep" variability in the residual (see Enders and Granger, 1998; and Enders and Siklos, 2001). The existence of "negative deepness" $\left(\left|\psi_{1}\right| \leq\left|\psi_{2}\right|\right)$ implies increases are persistent, and decreases move faster to equilibrium. The MTAR model offer valuable insight when the adjustment mechanism exhibits great momentum in one direction, as opposed to the other (see Enders and Granger, 1998).

There are two options for specifying the value of the threshold, $\tau$, for both the TAR and MTAR models. First, $\tau$ can be set to zero (i.e. $\tau=0$ ); in which case, the names of both models remain unchanged. And, second, the value of $\tau$ is determined by the dataset using a search method proposed by Chan (1993). If the threshold value is determined this way, the resulting models are known as the consistent TAR and MTAR models. ${ }^{2}$ The procedure for obtaining the threshold value following Chan (1993) takes some steps. The threshold variable, $\hat{\mu}_{t-1}$ for TAR, and $\Delta \hat{\mu}_{t-1}$ for MTAR, must first be sorted in ascending order. The potential threshold values are then determined. Enders (2004) recommends that the threshold variable crosses the threshold value. In other words, the threshold value should lie between the minimum and the maximum values of the threshold variable. The practical way of doing this is by jettisoning the lowest and highest $15 \%$ of the threshold values during the search, in order to allow for sufficient observations on either side of the sample. Finally, the values of the threshold variable that fall within the middle

\footnotetext{
${ }^{2}$ Chan (1993), indeed, demonstrates that the threshold value is superconsistent if it results from the minimum sum of squared errors of the fitted model after searching over the potential threshold values (see also Enders and Siklos, 2001).
} 
$70 \%$ bands are used as likely threshold values to estimate the consistent TAR and MTAR models.

From this brief discussion, it implies that we are going to test for nonlinear cointegration using four models: (i) TAR with $\tau=0$; (ii) consistent TAR with estimated $\tau$; (iii) MTAR with $\tau=0$; and (iv) consistent MTAR with estimated $\tau .{ }^{3}$ The decision on which model fits the data well is best taken by considering the AIC and BIC information criteria (see Enders and Siklos, 2001). Thus, the model with the minimum AIC and BIC is the best model.

Finally, the nonlinear cointegration could be examined using two tests. The first test entails the null hypothesis, $H_{0}: \psi_{1}=\psi_{2}=0$, of no cointegration against the alternative of cointegration with TAR or MTAR adjustment scheme. This is a non-standard $F$-test with test statistic $\Phi$ and critical values reported in Enders and Siklos (2001). The second test entails the null hypothesis, $H_{0}: \psi_{1}=\psi_{2}$, of linear equilibrium adjustment scheme against a nonlinear adjustment scheme alternative. This test follows a standard $F$-distribution.

\subsection{Nonlinear Error Correction Estimation}

The normal step to follow, if nonlinear cointegrating relationship is establish between the time series, is to estimate a representative error correction model as per the Engle-Granger representation theorem (see Engle and Granger, 1987). In the nonlinear setting, error-correction modelling is a relatively new concept. Granger and Lee (1989) developed an extension to the error correction mechanism in Engle and Granger (1987) to account for asymmetric adjustments. The main idea in Granger and Lee (1989) is that negative shocks and positive shocks affect the long-run adjustment differently. Thus, they decompose the error correction terms and the first

\footnotetext{
${ }^{3}$ See Sun (2011), for similar discussion.
} 
difference terms of the series into positive and negative components. They then examine whether or not the positive and negative components have asymmetric impact on the equilibrium adjustment. The other extension stems from the threshold cointegration literature. This extension proposes a modification of the error correction terms to account for threshold effects (see Balke and Fomby, 1997; Enders and Granger, 1998). Following these extension, a representative error correction model which accounts for both threshold effects and asymmetric dynamics is specified of the form:

$$
\begin{aligned}
& \Delta y_{t}=\eta_{11}+\varpi_{11}^{+} E_{t-1}^{+}+\varpi_{12}^{-} E_{t-1}^{-}+\sum_{j=1}^{J} \varphi_{j 1}^{+} \Delta y_{t-j}^{+}+\sum_{j=1}^{J} \varphi_{j 2}^{-} \Delta y_{t-j}^{-}+\sum_{j=1}^{J} \Theta_{j 1}^{+} \Delta x_{t-j}^{+}+\sum_{j=1}^{J} \Theta_{j 2}^{-} \Delta x_{t-j}^{-}+v_{t 1} \\
& \Delta x_{t}=\eta_{21}+\varpi_{21}^{+} E_{t-1}^{+}+\varpi_{22}^{-} E_{t-1}^{-}+\sum_{j=1}^{J} \varphi_{j 3}^{+} \Delta y_{t-j}^{+}+\sum_{j=1}^{J} \varphi_{j 4}^{-} \Delta y_{t-j}^{-}+\sum_{j=1}^{J} \Theta_{j 3}^{+} \Delta x_{t-j}^{+}+\sum_{j=1}^{J} \Theta_{j 4}^{-} \Delta x_{t-j}^{-}+v_{t 2}
\end{aligned}
$$

where $\Delta y_{t}$ and $\Delta x_{t}$ are the first difference of the series, $\eta, \varpi, \varphi$, and $\Theta$ are coefficients to be estimated, $J$ is the number of lags to be included, $t$ is the time subscript, and $v$ denotes the whitenoise error term. The choice of $J$, the number of lags, is determined by the AIC, BIC and the Ljung-Box Q test. The lagged first difference series, $\Delta y_{t-j}$ and $\Delta x_{t-j}$, are decomposed into positive and negative components. The error correction terms $E_{t-1}$ are also decomposed into positive and negative components such that $E_{t-1}^{+}=I_{t} \hat{\mu}_{t-1}$ and $E_{t-1}^{-}=\left(1-I_{t}\right) \hat{\mu}_{t-1}$ following the threshold cointegration specifications in (8), (9a), and (9b). This decomposition ensures that asymmetric shocks (both negative and positive), and threshold effects are incorporated into the error correction model (see Sun, 2011; for a similar explanation). $\varpi_{11}$ and $\varpi_{12}$ will be positive, and $\varpi_{21}$ and $\varpi_{22}$ negative, if $y_{t}$ drives the cointegrating relationship. The reverse holds, if $x_{t}$ drives the cointegrating relationship (see Enders and Siklos, 2001). 
The test of Granger causality could be carried out by setting: (i) $\varphi_{j 1}^{+}=\varphi_{j 2}^{-}=0$ implying that $y_{t}$ does not cause itself or $\Theta_{j 1}^{+}=\Theta_{j 2}^{-}=0$ implying that $x_{t}$ does not cause $y_{t}$; and (ii) $\Theta_{j 3}^{+}=\Theta_{j 4}^{-}=0$ implying that $x_{t}$ does not cause itself or $\varphi_{j 3}^{+}=\varphi_{j 4}^{-}=0$ implying that $y_{t}$ does not cause $x_{t}$. Next, distributed lag asymmetric effect could be tested. For instance, we set $\varphi_{11}^{+}=\varphi_{12}^{-}$to test the hypothesis that at first lag, $y_{t}$ has symmetric effect on itself; the process is replicated for each lag and for $\Theta_{j 1}^{+}=\Theta_{j 2}^{-}$- the symmetric or asymmetric effect of $x_{t}$ on $y_{t}$ at the $j t h$ lag. We could also test for the cumulative symmetric effect of $y_{t}$ on itself by setting $\sum_{j=1}^{J} \varphi_{j 1}^{+}=\sum_{j=1}^{J} \varphi_{j 2}^{-}$; the cumulative symmetric effect of $x_{t}$ on $y_{t}$ by setting $\sum_{j=1}^{J} \Theta_{j 1}^{+}=\sum_{j=1}^{J} \Theta_{j 2}^{-}$; the cumulative symmetric effect of $y_{t}$ on $x_{t}$ by setting $\sum_{j=1}^{J} \varphi_{j 3}^{+}=\sum_{j=1}^{J} \varphi_{j 4}^{-}$; and the cumulative symmetric effect of $x_{t}$ on itself by setting $\sum_{j=1}^{J} \Theta_{j 3}^{+}=\sum_{j=1}^{J} \Theta_{j 4}^{-}$. Finally, we could test for asymmetric equilibrium path by setting $\varpi_{11}=\varpi_{12}$ for $(10 \mathrm{a})$ and $\varpi_{21}=\varpi_{22}$ for $(10 \mathrm{~b})$.

\subsection{Data}

The data on the two interest-rate series are extracted from the International Financial Statistics (IFS) database compiled by the IMF. The SARB policy rate is labelled as South Africa - Central Bank Policy Rates: Central Bank Policy Rate (EOP) (Percent Per Annum), and the yield on longterm government bonds is labelled as South Africa - Government Bonds Yields: Government Bonds Yield (Percent Per Annum) in the IFS database. Our choice of the IFS database is informed by the fact that it is one of the consistent, reliable, and accessible databases in the world. The sample period spans January 1957 to February 2015. This is the longest sample span we could get, to the best of our knowledge. 


\section{Results}

\subsection{Descriptive Statistics}

The key highlights of South African Reserve Bank's policy rate (SARB policy rate) and the yield on long-term government bonds are shown in Table 1. The SARB policy rate has average about 9.280\%, whereas the yield on long-term government bonds averaged about $10.368 \%$ over the sample period (i.e. from January 1957 to February 2015). Thus, over the sample period, the SARB policy has been $1.088 \%$ lower, on the average, than the yield on long-term government bonds. This makes theoretical sense because lenders will generally demand higher interest on long-term loans due to the higher risks associated with them.

The maximum interest rate recorded for the period was $21.85 \%$ for the SARB policy rate, and $18.30 \%$ for the long-term bonds yield. This occurred around August and September 1998 (see Figure 1). Theoretically, when short-term interest rates exceed long-term interest rates (resulting in an inverted yield curve), the economy is likely to plunge into recession. In the South African case, it seems that market participants anticipated falling interest rates post-apartheid. Indeed, from 1998 onwards, both the SARB policy rate and the yield on long-term bonds have experience rapid declines. Not surprisingly, the mild South African recession began to manifest during this period (see Venter and Pretorius, 2004). The figures for both interest rates at the end of the sample period are almost identical to the pre-1980 figures. The minimum value recorded for each interest rate during the period under the study is $4.75 \%$ and $2.22 \%$ for the yield on longterm government bonds and the SARB policy rate, respectively. 
Table 1: Descriptive Statistics of the Interest-Rate Series

\begin{tabular}{lcc}
\hline Statistic & Long-term Bonds Yield & SARB Policy Rate \\
\hline Mean & 10.368 & 9.280 \\
Median & 9.335 & 7.730 \\
Maximum & 18.300 & 21.850 \\
Minimum & 4.750 & 2.220 \\
Std. Dev. & 3.917 & 4.793 \\
Skewness & 0.315 & 0.687 \\
Kurtosis & 1.799 & 2.374 \\
& & \\
Jarque-Bera & 53.532 & 66.304 \\
Probability & 0.000 & 0.000 \\
& & \\
Sum & 7236.850 & 6477.460 \\
Sum Sq. Dev. & 10692.620 & 16015.210 \\
Observations & 698 & 698 \\
\hline
\end{tabular}

Note: Std. Dev. and Sum Sq. Dev. denote standard deviation and sum of squared deviations, respectively.

Figure 1 traces out the movements of these interest rates from January 1957 to February 2015. These curves are sometimes collectively known as the term structure of interest rates ${ }^{4}$ in the finance literature (see Estrella and Mishkin, 1997). By ocular inspection of Figure 1, we can see that the two curves are inverted to the term or time-to-maturity axis, indicating that at some point over the sample period, the SARB policy rate has exceeded the yield on long-term government bonds. Nel (1996) argues that the nature of the inverted yield curve is in line with the gradual introduction of the current market-oriented monetary control mechanism recommended by the De Kock Commission, which allowed the South African Reserve Bank (SARB) to liberate the interest rates to fluctuate with the business cycle. Nevertheless, this is rather peripheral to our study. Our main focus is how the two interest rates move overtime. It is very clear from Figure 1 that the two interest-rate series are highly associated. This association has been a subject of

\footnotetext{
${ }^{4}$ Term structure of interest rates (also known as the yield curve) is the relationship between interest rates or bond yields and their maturities (see Taylor, 1992).
} 
empirical investigations in the literature. The general consensus is that interest-rate series are non-stationary I(1) processes which should move together in the long run (see Stock and Watson, 1988). However, the standard approach to verifying the cointegrating or long-run behaviour of these interest-rate series is what has steered controversies in the literature. In the next few sections, we will present the results of the asymmetric approach we believe may be appropriate for examining the term structure of interest rates of South Africa.

Figure 1: The SARB Policy Rate and the Yield on Long-term Government Bonds

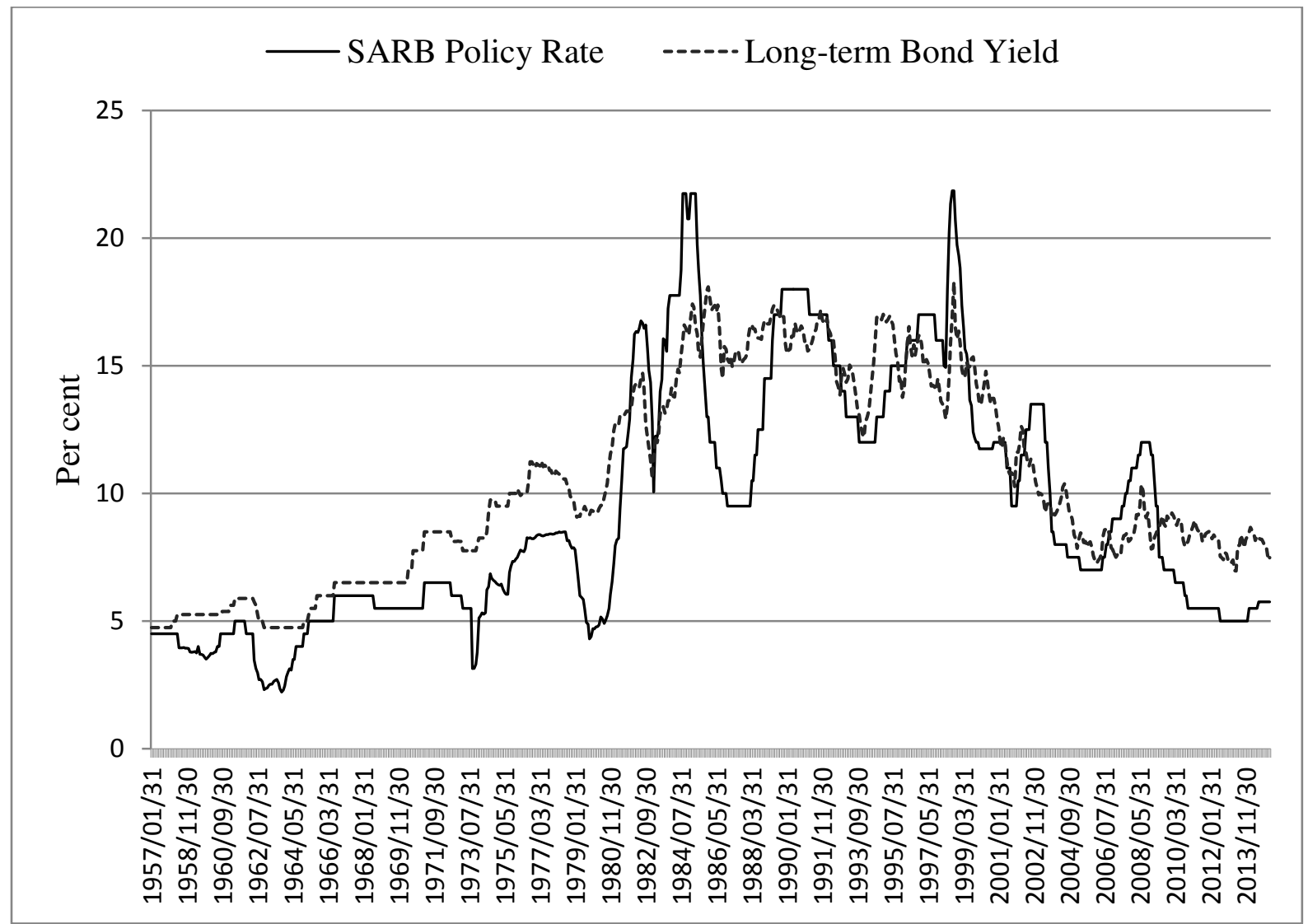

Source: The International Financial Statistics, IMF (2015). 


\subsection{Results of Unit Root Tests}

Although interest-rate series are generally known to be I(1) processes (see Stock and Watson, 1988), it is necessary to avoid pitfalls by first establishing this fact in the series we employ here. Note that from this point onwards the interest-rate series are in natural logarithms. Table 2 shows the results of the unit root tests we have discussed in the methodology section. The linear unit root test failed to reject the presence of unit roots in both series at the conventional level of significance. The asymmetric unit root test of Kapetanios et al. (2003) also failed to reject the presence of unit roots in the two interest-rate series. However, the follow-up tests show that the two interest-rate series are I(1) processes at $1 \%$ significance level (see Table 2).

Table 2: Results for Linear and Nonlinear Unit Root Tests

\begin{tabular}{lllll}
\hline Tests & SARB Level & SARB Difference & Bonds Level & Bonds Difference \\
\hline DF-GLS [Drift] & -1.595 & $-7.641^{* * *}$ & -0.536 & $-19.780 * * *$ \\
DF-GLS [Trend] & -2.415 & $-7.648^{* * *}$ & -0.789 & $-19.742 * * *$ \\
Ng-Perron [Drift] & -5.403 & $-79.491 * * *$ & -0.698 & $-27.160 * * *$ \\
Ng-Perron [Trend] & -14.158 & $-79.693 * * *$ & -1.990 & $-26.947 * * *$ \\
KSS & 0.146 & NA & 0.456 & NA \\
\hline Not
\end{tabular}

Note: NA denotes non-applicable. The critical values for KSS are compared to Table 1 [Case 1] in Kapetanios et al. (2003, p. 364). *** denotes significance at $1 \%$ level.

\subsection{Results of Linear Cointegration Tests}

We have established that the two interest-rate series are I(1), thus far. Now, we want to verify whether the two interest-rate series are cointegrated. Because series of this kind are known to exhibit nonlinear adjustment towards equilibrium, linear cointegration tests may fail to establish 
a long-run relationship between them. Hence, we first present results of the linear cointegration tests (i.e. the Johansen and the Engle-Granger two-step cointegration tests), then we present those of the nonlinear cointegration test. Table 3 reports the results of the Johansen test for cointegrating relationships. The maximum eigen value statistic $\left(\lambda_{\max }\right)$ is reported at the upper panel, whilst the trace statistic $\left(\lambda_{\text {trace }}\right)$ is reported at the lower panel. The Johansen test establishes a fairly strong cointegrating relationship between the SARB policy rate and the yield on the long-term government bonds. For instance, with drift term included, the trace statistic ( $\lambda_{\text {trace }}$ ) is 21.45 and the maximum eigen value statistic $\left(\lambda_{\max }\right)$ is 18.086 for the null hypothesis of no cointegrating relationship. Thus, the trace and maximum eigen value statistics reject the null hypothesis of no cointegration. The results for the Engle-Granger two-step test are reported in Panel [1] of Table 4. The statistic of this residual unit root test $\psi$ is -0.032 which is significant at 5\% level. Thus, the Engle-Granger two-step test confirms that the two-interest rate series are cointegrated.

Table 3: Results of Johansen Cointegration Test

\begin{tabular}{|c|c|c|c|c|c|}
\hline \multirow[t]{2}{*}{ Test } & \multirow[t]{2}{*}{ Specification } & \multicolumn{3}{|c|}{ Critical Value } & \multirow[b]{2}{*}{$1 \%$} \\
\hline & & Statistic & $10 \%$ & $5 \%$ & \\
\hline \multicolumn{6}{|c|}{ Johansen $\lambda_{\max }$} \\
\hline $\mathrm{r}=1$ & Constant & 3.364 & 7.52 & 9.24 & 12.97 \\
\hline $\mathrm{r}=0$ & Constant & $18.086 * *$ & 13.75 & 15.67 & 20.2 \\
\hline $\mathrm{r}=1$ & None & 3.177 & 6.5 & 8.18 & 11.65 \\
\hline $\mathrm{r}=0$ & None & $18.051 * *$ & 12.91 & 14.9 & 19.19 \\
\hline \multicolumn{6}{|c|}{ Johansen $\lambda_{\text {trace }}$} \\
\hline $\mathrm{r} \leq 1$ & Constant & 3.364 & 7.52 & 9.24 & 12.97 \\
\hline$r=0$ & Constant & $21.45 * *$ & 17.85 & 19.96 & 24.6 \\
\hline $\mathrm{r} \leq 1$ & None & 3.177 & 6.5 & 8.18 & 11.65 \\
\hline$r=0$ & None & $21.228 * *$ & 15.66 & 17.95 & 23.52 \\
\hline
\end{tabular}

Note: $\mathrm{r}$ is the number of cointegrating vectors; ** denotes significance at $5 \%$. 


\subsection{Results of the Nonlinear Cointegration Test}

We examine the possibility of nonlinear cointegrating relationships between the two interest-rate series using the threshold models discussed in the methodology section. The results of the four threshold models are shown in Panels [2] to [5] in Table 4. 12 lags were included in the original models but the multivariate AIC, BIC and the Ljung-Box Q statistic indicated that a maximum of 4 lags are sufficient for this analysis.

Next, we estimate the TAR model with $\tau=0$ and report that in Panel [2] of Table 4. The point estimates of $\psi_{1}=-0.036$ and $\psi_{2}=-0.035$ imply that there is convergence. Also, the threshold cointegration test statistic, $\Phi=7.798$, is greater than the critical value at $5 \%$ (i.e. 6.33). Thus, the null hypothesis of no cointegration between the SARB policy rate and the yield on long-term government bonds could be rejected. Yet, the adjustment process to equilibrium is symmetric, since the p-value reported for the $F$-statistic is greater than 0.05 (see Panel [2] in Table 4). Panel [4] reports the results for the MTAR model with $\tau=0$. Here too, the point estimates of $\psi_{1}=-0.028$ and $\psi_{2}=-0.045$ imply that there is convergence. Similarly, $\Phi=8.281$ is greater than the critical value at $5 \%$ (i.e. 6.05 ). Therefore, we can reject the null hypothesis of no cointegration between the SARB policy rate and the yield on long-term government bonds. The adjustment process to equilibrium is symmetric, since the p-value (0.331) reported for the $F$-statistic is greater than 0.05 .

Panels [3] and [5] show the results for TAR and MTAR models with unknown $\tau$. Here, Chan's (1993) search method is deployed to arrive at consistent estimates of the threshold. The search for the possible thresholds lying in the middle $70 \%$ bands of the residuals revealed that the consistent threshold for the TAR model is -0.202 ; and the consistent threshold for the MTAR 
model is -0.018 . These threshold values yielded the smallest residual sum of squares for the TAR and MTAR models. The point estimates of $\psi_{1}=-0.029$ and $\psi_{2}=-0.043$ for the consistent TAR model imply that there is convergence; the point estimates also suggest that the speed of adjustment is faster for negative than for positive discrepancies. In addition, $\Phi=8.159$ is greater than the critical value near 5\% level (i.e. 7.56), implying that we can reject the null hypothesis of no cointegration between the SARB policy rate and the yield on long-term government bonds. There is symmetric adjustment to equilibrium because the p-value $(0.401)$ associated with the $F$-statistic is greater than 0.05 (see Panel [3]).

Finally, the point estimates of $\psi_{1}$ and $\psi_{2}$ for the MTAR indicate convergence. That aside, the speed of adjustment is faster for negative than for positive discrepancies. The estimated value of $\Phi$ is 9.287 which is greater than the critical value near $1 \%$ level (i.e. 8.47). Thus, the null hypothesis of no cointegration between the SARB policy rate and the yield on long-term government bonds can be rejected. The adjustment mechanism for the two interest-rate series is asymmetric, since the p-value (0.088) associated with the $F$-statistic is less than 0.10 (see Panel [5]). Using the AIC, BIC, and the Ljung-Box Q statistic, the MTAR model with $\tau=-0.018$ (i.e. the consistent MTAR model) fits our data better than the other three threshold models. This suggests that positive deviations from the long-term equilibrium due to increases in the SARB policy rate or decreases in the yield on long-term government bonds $\left(\Delta \hat{\mu}_{t-1} \geq-0.018\right)$ are corrected at $2.6 \%$ per month. Negative deviations from the long-term equilibrium due to decreases in the SARB policy rate or increases in the yield on long-term government bonds $\left(\Delta \hat{\mu}_{t-1}<-0.018\right)$ are corrected at $6 \%$ per month. 
Table 4: Results of Engle-Granger and Nonlinear Cointegration Tests

\begin{tabular}{|c|c|c|c|c|c|}
\hline & [1] & [2] & [3] & [4] & [5] \\
\hline Item & Engle-Granger & TAR & Consistent TAR & MTAR & Consistent MTAR \\
\hline Lag & NA & 4 & 4 & 4 & 4 \\
\hline Threshold & NA & 0 & -0.202 & 0 & -0.018 \\
\hline$\psi_{1}$ & $\begin{array}{l}-0.032 * * \\
(-3.69)\end{array}$ & $\begin{array}{l}-0.036 * * * \\
(-2.784)\end{array}$ & $\begin{array}{l}-0.029 * * \\
(-2.385)\end{array}$ & $\begin{array}{l}-0.028 * * \\
(-2.29)\end{array}$ & $\begin{array}{l}-0.026 * * \\
(-2.554)\end{array}$ \\
\hline$\psi_{2}$ & NA & $\begin{array}{l}-0.035^{* * *} \\
(-2.902)\end{array}$ & $\begin{array}{l}-0.043 * * * \\
(-3.345)\end{array}$ & $\begin{array}{l}-0.045^{* * * *} \\
(-3.424)\end{array}$ & $\begin{array}{l}-0.060 * * * \\
(-3.55)\end{array}$ \\
\hline \multicolumn{6}{|l|}{ Diagnostics } \\
\hline AIC & -2150.103 & -2140.662 & -2141.373 & -2141.613 & -2143.592 \\
\hline BIC & -2136.458 & -2108.874 & -2109.586 & -2109.826 & -2111.805 \\
\hline$Q_{L B}(4)$ & 0.053 & 0.995 & 0.996 & 0.992 & 0.987 \\
\hline$Q_{L B}(8)$ & 0.077 & 0.462 & 0.450 & 0.417 & 0.438 \\
\hline$Q_{L B}(12)$ & 0.030 & 0.119 & 0.122 & 0.104 & 0.100 \\
\hline \multicolumn{6}{|l|}{ Hypotheses } \\
\hline$\left.=\psi_{2}=0\right)$ & NA & $7.798 * *$ & $8.159 * *$ & $8.281 * *$ & $9.287 * * *$ \\
\hline $\mathrm{CV}(1 \%)$ & & 9.09 & 10.18 & 8.31 & 8.47 \\
\hline $\mathrm{CV}(5 \%)$ & & 6.33 & 7.56 & 6.05 & 6.32 \\
\hline $\begin{array}{l}F\left(H_{0}: \psi_{1}\right. \\
\left.=\psi_{2}\right) \\
\text { p-value }\end{array}$ & NA & $\begin{array}{l}0.002 \\
0.968\end{array}$ & $\begin{array}{l}0.708 \\
0.401\end{array}$ & $\begin{array}{l}0.946 \\
0.331\end{array}$ & $\begin{array}{l}2.913^{*} \\
0.088\end{array}$ \\
\hline
\end{tabular}

Note:

a) $\quad \psi_{1}=\psi_{2}$ for the Engle-Granger cointegration test, so that we report only $\psi_{1}=\psi$.

b) $Q_{L B}(p)$ denotes significance level for the Ljung-Box Q-statistic for the $\mathrm{p}^{\text {th }}$ autocorrelation coefficient $(\mathrm{p}=$ $4,8,12)$.

c) $\Phi$ is the threshold cointegration test statistic whose critical values are reported from Tables 1 and 5 of Enders and Siklos (2001).

d) $F$ denotes the test of asymmetric adjustment to equilibrium.

e) $\mathrm{t}$-statistics are reported in the parentheses.

f) $*, * *$ and $* * *$ denote significance at $10 \%, 5 \%$ and $1 \%$, respectively.

\subsection{Results of the Asymmetric Error Correction Model}

In this section, we present and assess the threshold error correction model for the two interestrate series. We proceed on the basis that the model which fits the data best is the consistent MTAR model. The AIC, BIC, and the Ljung-Box statistic indicate that four lags are sufficient for the asymmetric momentum threshold error correction model. Table 5 reports the estimates of 
the error correction model. Nine coefficients are significant at conventional levels in the SARB policy rate equation (i.e. $\Theta_{1}^{+}, \Theta_{3}^{-}, \Theta_{4}^{-}, \varphi_{1}^{+}, \varphi_{2}^{+}, \varphi_{1}^{-}, \varphi_{2}^{-}, \varphi_{4}^{-}$, and $\varpi^{-}$). In the yield on long-term government bonds equation, five coefficients are significant at conventional levels (i.e. $\Theta_{1}^{+}, \Theta_{1}^{-}$, $\Theta_{2}^{-}, \Theta_{3}^{-}$, and $\left.\varphi_{1}^{+}\right)$. We report $R^{2}$ of 0.142 and 0.115 for the SARB policy rate and the long-term bonds yield equations, respectively. Thus, the model is better specified for the SARB policy rate as compared to the long-term bonds yield. This is to be expected as the SARB policy rate equation acts as a reaction function for the SARB, in response to changing economic conditions. In addition to this, the point estimates of the adjustment terms have the correct signs. Since the long-term bonds yield drives the cointegrating relationship, the error correction terms are positive whereas the error correction terms in the SARB policy rate equation are negative (see Table 5).

Next, we consider the series of hypotheses tested. $\mathrm{H}_{01}$ and $\mathrm{H}_{02}$ are the hypotheses for Granger Causality between the two interest-rate series. The corresponding $F$-statistic (i.e. 2.373 ) for $\mathrm{H}_{01}$ with a p-value of 0.02 indicates that there is a causal flow from the yield on long-term government bonds to the $\mathrm{SARB}$ policy rate. The $F$-statistic (i.e. 1.394) for $\mathrm{H}_{02}$ with a p-value of 0.20 implies that there is no causal flow from the SARB policy rate to the long-term bonds yield. In addition, we see that each interest-rate series is influenced by its lags. This is indicated by the $F$-statistic of 7.047 and 8.565 for the SARB policy rate and the long-term bonds yield, respectively. These results are consistent with those presented in Enders and Siklos (2001). On account of this evidence, we claim that the SARB policy rate depends largely on the long-term bonds yield in the short-term. This reflects the monetary policy framework pursued by the South African Reserve Bank. The SARB policy rate is frequently determined by the Monetary Policy Committee (MPC) in response to changing market conditions which include the movements in 
long-term government bonds yield (see Nel, 1996). However, the long-term government bonds yield is determined by markets forces (see SARB Fact Sheets, 2007).

The other tests examine possible asymmetric effects. For instance, $\mathrm{H}_{03}$ and $\mathrm{H}_{04}$ are hypotheses for distributed lag asymmetric effect. We do not find any distributed lag asymmetric effect for the long-term government bonds yield but we do find distributed lag asymmetric effect for SARB policy rate on itself at $1 \%$ significance level. Similarly, $\mathrm{H}_{05}$ and $\mathrm{H}_{06}$ are hypotheses for cumulative lag asymmetric effects. The $F$-statistic of 4.393 and 7.126 for the SARB policy rate equation implies that cumulative lag effects from the long-term bonds yield and the SARB policy rate, respectively, are asymmetric on the SARB policy rate. The $F$-statistics of 1.086 and 2.285 for the long-term government bonds yield equation simply indicate that cumulative lag effects from long-term government bonds yield and the SARB policy rate, respectively, are symmetric on the long-term government bonds yield at conventional levels.

Finally, we verify the equilibrium adjustment path asymmetries. $\mathrm{H}_{07}$ is the hypothesis for asymmetric adjustment to equilibrium effect. The $F$-statistic for the SARB policy rate is 2.192 with a p-value of 0.14 . The corresponding error correction term is -0.016 with a $t$-statistic of 1.573 for positive discrepancies and -0.043 with a $t$-statistic of -2.709 for negative discrepancies. Also, the $F$-statistic for the long-term government bonds yield is 0.869 with a p-value of 0.35 . The error correction term is 0.003 with a p-value of 0.497 for positive discrepancies and 0.013 with a p-value of 1.395 for negative discrepancies. Thus, there is no momentum equilibrium adjustment asymmetry. These findings cast doubt on the strength of the consistent MTAR test we presented above. Intuitively, our asymmetric error correction model collapses to a linear one, since the momentum equilibrium adjustment mechanism is symmetric. In the next section, we 
look at the nature of the linear error correction model as compared to the asymmetric error correction model.

Table 5: Asymmetric Error Correction Model with Threshold Adjustments

\begin{tabular}{|c|c|c|c|c|}
\hline \multirow[t]{2}{*}{ Item } & \multicolumn{2}{|l|}{ SARB Rate } & \multicolumn{2}{|c|}{ Bonds Yield } \\
\hline & Estimate & t-statistic & Estimate & t-statistic \\
\hline$\eta$ & 0.001 & 0.198 & 0.001 & 0.361 \\
\hline$\Theta_{1}^{+}$ & $0.245 * *$ & 2.230 & $0.211 * * *$ & 3.380 \\
\hline$\Theta_{2}^{+}$ & -0.152 & -1.384 & -0.052 & -0.829 \\
\hline$\Theta_{3}^{+}$ & -0.019 & -0.177 & 0.099 & 1.601 \\
\hline$\Theta_{4}^{+}$ & -0.064 & -0.582 & -0.060 & -0.958 \\
\hline$\Theta_{1}^{-}$ & 0.179 & 1.459 & $0.422 * * *$ & 6.056 \\
\hline$\Theta_{2}^{-}$ & -0.064 & -0.503 & $-0.219 * * *$ & -3.014 \\
\hline$\Theta_{3}^{-}$ & $0.227 *$ & 1.758 & $0.125^{*}$ & 1.706 \\
\hline$\Theta_{4}^{-}$ & $0.217 *$ & 1.734 & 0.026 & 0.364 \\
\hline$\varphi_{1}^{+}$ & $0.164 * * *$ & 2.602 & $0.059^{*}$ & 1.653 \\
\hline$\varphi_{2}^{+}$ & $0.213^{* * *}$ & 3.365 & 0.022 & 0.608 \\
\hline$\varphi_{3}^{+}$ & 0.028 & 0.438 & -0.005 & -0.144 \\
\hline$\varphi_{4}^{+}$ & 0.088 & 1.404 & -0.020 & -0.560 \\
\hline$\varphi_{1}^{-}$ & $0.13 * *$ & 2.424 & -0.045 & -1.483 \\
\hline$\varphi_{2}^{-}$ & $0.099^{*}$ & 1.869 & 0.044 & 1.487 \\
\hline$\varphi_{3}^{-}$ & 0.073 & 1.385 & -0.048 & -1.602 \\
\hline$\varphi_{4}^{-}$ & $-0.187 * * *$ & -3.516 & -0.017 & -0.557 \\
\hline$\varpi^{+}$ & -0.016 & -1.573 & 0.003 & 0.497 \\
\hline$\varpi^{-}$ & $-0.043 * * *$ & -2.709 & 0.013 & 1.395 \\
\hline$R^{2}$ & 0.142 & NA & 0.115 & NA \\
\hline AIC & -2238.855 & NA & -3025.578 & NA \\
\hline BIC & -2148.034 & NA & -2934.758 & NA \\
\hline$Q_{L B}(4)$ & 0.597 & NA & 0.999 & NA \\
\hline$Q_{L B}(8)$ & 0.000 & NA & 0.688 & NA \\
\hline$H_{01}: \Theta_{i}^{+}=\Theta_{i}^{-}=0$ for all lags & $2.373 * *$ & {$[0.02]$} & $8.565 * * *$ & {$[0.00]$} \\
\hline$H_{02}: \varphi_{i}^{+}=\varphi_{i}^{-}=0$ for all lags & $7.047 * * *$ & {$[0.00]$} & 1.394 & {$[0.20]$} \\
\hline$H_{03}: \Theta_{2}^{+}=\Theta_{2}^{-}$ & 0.221 & {$[0.64]$} & 2.522 & {$[0.11]$} \\
\hline$H_{04}: \varphi_{4}^{+}=\varphi_{4}^{-}$ & $10.444 * * *$ & {$[0.00]$} & 0.004 & {$[0.95]$} \\
\hline$H_{05}: \sum^{4} \Theta_{i}^{+}=\sum^{4} \Theta_{i}^{-}$ & $4.393^{* *}$ & {$[0.04]$} & 1.086 & {$[0.30]$} \\
\hline$H_{06}: \sum^{4} \varphi_{i}^{+}=\sum^{4} \varphi_{i}^{-}$ & $7.126 * * *$ & {$[0.01]$} & 2.285 & {$[0.13]$} \\
\hline$H_{07}: \varpi^{+}=\varpi^{-} \varpi_{i}$ & 2.192 & {$[0.14]$} & 0.869 & [0.35] \\
\hline
\end{tabular}

Note:

a) $\mathrm{H}_{01}$ and $\mathrm{H}_{02}$ are tests for Granger Causality.

b) $\mathrm{H}_{03}$ and $\mathrm{H}_{04}$ are tests for distributed lag asymmetric effect.

c) $\mathrm{H}_{05}$ and $\mathrm{H}_{06}$ are tests for cumulative asymmetric effect.

d) $\mathrm{H}_{07}$ is the test for asymmetric adjustment to equilibrium effect.

e) $*, * *$ and $* * *$ denote significance at $10 \%, 5 \%$ and $1 \%$, respectively.

f) P-values are in the parentheses.

g) NA denotes non-applicable. 


\subsection{Results of the Linear Error Correction Model}

From the above results, we find the asymmetric equilibrium adjustment mechanism to varnish when we fit the asymmetric error correction model. This suggests that the appropriate model which fits the term structure of interest rates in South Africa may not be asymmetric. To proceed, it is logical that we fit a linear error correction model for the interest rate series. Table 6 reports the linear error correction model ${ }^{5}$ with 4 lags for the term structure of interest rates in South Africa. Recall that the long-term government bonds yield is the driving force of the cointegrating relationship, thus the error correction term in the SARB policy rate equation must be negative and significant. Also, the error correction term in the long-term government bonds yield equation must be positive and not significant. We find this to be the case in our estimates. The error correction term is negative (i.e. -0.028) and significant at 5\% in the SARB policy rate equation; it is positive (i.e. 0.005) and insignificant in the long-term government bonds yield equation (see Table 6). The implication is that, each month, $2.8 \%$ of the deviations in the term structure of interest rates are corrected. These results are consistent with the results found in Arize et al. (2002).

The results indicate that the best fit model is the SARB policy rate equation since five coefficients are significant at the conventional levels. The lower panel of Table 6 reports the results for the linear Granger Causality tests. We find the long-term government bonds yield to Granger cause the SARB policy rate in the short run. This is indicated by an F-statistic of 2.718 with a $p$-value of 0.029 . In addition, we find a causal flow from long-term government bonds yield to the SARB policy rate in the long run (i.e. the error correction term in the SARPB policy rate equation is negative and significant at 5\%). However, the SARB policy rate does not

\footnotetext{
${ }^{5}$ Since this model is well-documented in the literature, we do not waste space by presenting it in this paper.
} 
Granger cause the long-term government bonds yield. These findings reinforce our earlier conclusion that the SARB policy rate largely depends on the long-term government bonds yield.

\section{Table 6: Linear Error Correction Model}

\begin{tabular}{lllll}
\hline Item & \multicolumn{3}{l}{ SARB Rate } & \multicolumn{2}{l}{ Bonds Yield } \\
\cline { 2 - 5 } & Estimate & t-statistic & Estimate & t-statistic \\
\hline$\eta$ & & & & \\
$\Theta_{1}$ & $0.145^{* * *}$ & 3.725 & 0.005 & 0.211 \\
$\Theta_{2}$ & $0.162^{* * *}$ & 4.130 & $0.038^{* * *}$ & 2.644 \\
$\Theta_{3}$ & $0.058^{* * *}$ & 1.482 & -0.029 & -1.298 \\
$\Theta_{4}$ & -0.071 & -1.831 & -0.021 & -0.948 \\
$\varphi_{1}$ & 0.226 & 3.234 & $0.312^{* * *}$ & 7.912 \\
$\varphi_{2}$ & -0.118 & -1.602 & $-0.117^{*}$ & -2.842 \\
$\varphi_{3}$ & $0.106^{*}$ & 1.441 & $0.109^{* * *}$ & 2.644 \\
$\varphi_{4}$ & 0.090 & 1.259 & -0.022 & -0.541 \\
$\varpi$ & $-0.028^{* *}$ & -3.443 & 0.005 & 1.055 \\
& & & & \\
Hypothesis & & & & \\
$\Theta_{i}=\Theta_{i}=0$ for all lags & $13.688^{* * *}$ & {$[0.000]$} & $2.718^{* *}$ & {$[0.029]$} \\
$\varphi_{i}=\varphi_{i}=0$ for all lags & 1.256 & {$[0.165]$} & $17.603^{* * *}$ & {$[0.000]$} \\
\hline
\end{tabular}

Note:

a) $* * *$ and $* * *$ denote significance at $10 \%, 5 \%$ and $1 \%$, respectively.

b) The restrictions in the lower panel are the Granger Causality tests; the reported statistics are F-statistics.

c) p-values are reported in the block parentheses.

\section{Concluding Remarks}

Majority of the studies on the cointegrating relationships between macroeconomic variables have presumed that the underlying relationships are linear. However, there have been important studies that have shown that most macroeconomic variables exhibit nonlinear adjustments over the business cycle (see Enders and Siklos, 2001). This remarkable revelation raises an important policy question mark on the empirical findings from the linear cointegration literature. 
One of the most studied issues in empirical finance in which linear cointegrating tests are vastly employed is the term structure of interest rates (see MacDonald and Speight, 1988; McFadyen et al., 1991; Hall et al., 1992; Wallace and Warner, 1993; Mandeno and Giles, 1995; and Arize et al., 2002; for example). Because the co-movements of interest-rate series are very important in policymaking (see McCallum, 1983; Bernanke and Blinder, 1989; Estrella and Mishkin, 1997, and Piazzesi, 2010), appropriate assumptions must be made in order to arrive at sound conclusions. Enders and Siklos (2001) identify this need and propose a better model to capture the long-run nonlinear co-movements of interest-rate series.

The literature on interest rates co-movements (and to some extent their nonlinear equilibrium adjustments) is still very limited in the South African context. The key studies on this issue are Arize et al. (2002) and Dube and Zhou (2013). Arize et al. (2002) employ linear cointegration techniques to explore the long-run movement of short- and long-term interest rates in 19 countries including South Africa, whereas Dube and Zhou (2013) utilize a two-regime threshold cointegration technique and the Hansen-Seo algorithm to examine whether short- and long-term interest rates co-move in South Africa. We add to this growing literature by exploring the term structure of interest rates in South Africa within a nonlinear setting slightly different from Dube and Zhou (2013).

We proceed with our analysis in a stepwise fashion. First, we examine the stationary properties of the interest rate series (namely, the SARB policy rate and the yield on long-term government bonds) using linear and nonlinear unit root tests and find the two interest-rate series to be firstdifference stationary or I(1) processes under both unit root tests. Next, we test for cointegrating relationships between the interest-rate series using linear and nonlinear cointegration techniques and find the evidence of cointegrating relationship between the two interest-rate series to be 
fairly strong when we utilize the linear Johansen cointegration test. In addition, the evidence of cointegrating relationship between the interest rate series is strongly supported by the nonlinear cointegration test of Enders and Siklos (2001). The nonlinear cointegration results imply that positive deviations from the long-term equilibrium due to increases in the SARB policy rate or decreases in the yield on long-term government bonds are corrected at $2.6 \%$ per month. Negative deviations from the long-term equilibrium due to decreases in the SARB policy rate or increases in the yield on long-term government bonds are corrected at $6 \%$ per month.

Because the interest rate series are cointegrated with threshold adjustment, we estimate the corresponding nonlinear error correction model. The results imply that there is a distinct causal flow from the yield on long-term government bonds to the SARB policy rate with momentum equilibrium adjustment symmetry. Hence, the asymmetric error correction model may not fit the interest rate series well, in the South African case. So we fit a linear error correction model and find short- and long-run causal flow from the long-term government bonds yield to the SARB policy rate. Our findings are consistent with the monetary policy framework pursued by the South African Reserve Bank (the SARB). The SARB policy rate is frequently determined by the Monetary Policy Committee (MPC) in response to changing market conditions which include the movements in long-term government bonds yield (see Nel, 1996). However, the long-term government bonds yield is determined by markets forces (see SARB Fact Sheets, 2007).

\section{Acknowledgments}

A previous version of this manuscript was published as ERSA Working Paper 557. The author thanks, without implicating, the editor of ERSA Working Papers, Professor Jan van Heerden, and an anonymous referee for their helpful comments and suggestions on the earlier version. All remaining shortcomings are regretfully the author's. 


\section{References}

Arize, A. C., Malindretos, J., and Obi, Z. K. (2002). Long and Short-Term Interest Rates in 19 Countries: Test of Cointegration and Parameter Instability. Atlantic Economic Journal 30(2): 105-120.

Aznar A., and Salvador M. (2002). Selecting the Rank of Cointegration Space and the Form of the Intercept Using an Information Criterion. Econometric Theory 18: 926-947.

Balke, N. S., and Fomby, T. (1997). Threshold Cointegration. International Economic Review 38: 627-645.

Bernanke, B. S. (1983). Non-Monetary Aspects of the Financial Crisis in the Propagation of the Great Depression. American Economic Review. 73: 257-276.

Bernanke, B. S. (1990). On The Predictive Power of Interest Rates and Interest Rate Spreads. New England Economic Review. Nov/Dec: 51-68.

Bernanke, B. S. and Blinder, A. S. (1989). The Federal Funds Rate And The Channels Of Monetary Transmission. Unpublished Paper. Princeton University, September.

Caner, M., and Kilian, L. (2001). Size Distortion of Tests of the Null Hypothesis of Stationarity: Evidence and Implication for the PPP Debate. Journal of International Money and Finance 20: 639-657.

Chan, K. S. (1993). Consistency and Limiting Distribution of the Least Squares Estimator of a Threshold Autoregressive Model. The Annals of Statistics 21: 520-533.

Chen, N-F. (1991). Financial Investment Opportunities and the Macroeconomy. Journal of Finance. 46: 529-544.

Dube, S., and Zhou, Y. (2013). South Africa's Short Term and Long Term Interest Rates: A Threshold Cointegration Analysis. Business and Economic Research 3(1): 187-211.

Enders, W. (2004). Applied Econometric Time Series, Second Ed. Wiley, New York.

Enders, W., and Granger, C. W. J. (1998). Unit-Root Tests and Asymmetric Adjustment with an Example Using the Term Structure of Interest Rates. Journal of Business \& Economic Statistics 16: $304-311$.

Enders, W., and Siklos, P. L. (2001). Cointegration and Threshold Adjustment. Journal of Business and Economic Statistics 19: 166-176. 
Engle, R. F., and Granger, C. W. J. (1987). Cointegration and Error Correction: Representation, Estimation, and Testing. Econometrica 55: 251-276.

Elliot, G., Rothenberg, T. J., and Stock, H. (1996). Efficient Tests for an Autoregressive Unit Root. Econometrica 64: 813-836.

Estrella, A. and Hardouvelis, G. (1991). The Term Structure as a Predictor of Real Economic Activity. The Journal of Finance, 46: 555-576.

Estrella, A. and Mishkin, F., 1997. The Predictive Power of the Term Structure of Interest Rates in Europe and the United States: Implications For The European Central Bank, European Economic Review, 41(7): 1357-1402.

Friedman, B. A. and Kuttner, K. N. (1989). Money, Income and Prices after the 1980's. National Bureau of Economic Research. Working Paper No. 2852, February.

Fuhrer, J. (1996). Monetary Policy Shifts and Long-Term Interest Rates. Quarterly Journal of Economics 1183-1209.

Fuhrer, J. and Moore, G. (1995). Monetary Policy Trade-Offs and the Correlation between Nominal Interest Rates and Real Output. American Economic Review 85: 219-239.

Gonzalo, J., and Pitarakis, J.-Y. (1998). Specification via Model Selection in Vector Error Correction Models. Economics Letters 60: 321-328.

Granger, C. W. J., and Lee, T. H. (1989). Investigation of Production, Sales, and Inventory Relationships Using Multicointegration and Non-symmetric Error-Correction Models. Journal of Applied Econometrics 4: S145-S159.

Hall, A. D., Anderson, H. M., and Granger, C. W. J. (1992). A Cointegration Analysis of Treasury Bill Yields. Review of Economics and Statistics 74: 117-126.

Harvey, C. R. (1989). Forecasts of Economic Growth from the Bonds and Stock Markets. Financial Analysts Journal 45: 38-45.

Johansen, S. (1988). Statistical Analysis of Cointegration Vectors. Journal of Economic Dynamics and Control 12: 231-254.

Johansen, S. (1991). Estimation and Hypothesis Testing of Cointegration Vectors in Gaussian Vector Autoregressive Models. Econometrica 59: 1551-1580. 
Johansen, S. (1995). Likelihood-Based Inference in Cointegrated Vector Autoregressive Models. Oxford: Oxford University Press.

Johansen, S., and Juselius, K. (1990). Maximum Likelihood Estimation and Inference on Cointegration with Applications to the Demand for Money. Oxford Bulletin of Economics and Statistics 52(2): 169-210.

Joyce, M., Lildholdt, P., and Sorensen, S. (2009). Extracting Inflation Expectations And Inflation Risk Premia From The Term Structure: A Joint Model of The UK Nominal And Real Yield Curves. Bank of England Working Paper No. 360, February.

Kapetanios G., Shin, Y., and Snell, A. (2003). Testing for a Unit Root in the Nonlinear STAR Framework. Journal of Econometrics 112: 359-379.

Kessel, R. A. (1965). The Cyclical Behaviour of the Term Structure of Interest Rates. National Bureau of Economic Research, Occasional Paper 91.

Khomo, M. M., and Aziakpono, M. J. (2007). Forecasting Recession in South Africa: a Comparison of the Yield and other Economic Indicators. South African Journal of Economics 75(2): 194-212.

Luukkonen, R., Saikkonen, P., Teräsvirta, T. (1988). Testing Linearity against Smooth Transition Autoregressive Models. Biometrika 75: 491-499.

MacDonald, R. and Speight, A. (1988). The Term Structure of Interest Rates in the UK," Bulletin of Economic Research 40: 287-299.

Mandeno, J., and Giles, E. A. (1995). The Expectations Theory of the Term Structure: a Cointegration/Causality Analysis of U.S. Interest Rates. Applied Financial Economics 5: 273283.

McCallum, B. (1983). A Reconsideration of Sim's Evidence Concerning Monetarism. Economic Letters 13:161-171.

McCallum, B. (1994). Monetary Policy and the Term Structure of Interest Rates, NBER Working Paper No. 4938.

McFadyen, J., Pickerill, K., and Devaney, M. (1991). The Expectations Hypothesis of the Term Structure: More Evidence. Journal of Economics and Business 43: 79-85.

McGough, B., Rudebusch, G., and Williams, J. (2005). Using a Long-Term Interest Rate as the Monetary Policy Instrument. Journal of Monetary Economics 52: 855-879. 
Moolman, E. (2002). The Term Structure as a Predictor of Recession. Journal for Studies in Economics and Econometrics 26(3): 43-51.

Mustafa, M., and Rahman, M. (1995). Cointegration Between U.S. Short-term and Long-term Interest Rates Both Nominal and Real. Applied Financial Economics 5: 323-327.

Nel, H. (1996). The Term Structure of Interest Rates and Economic Activity in South Africa. South African Journal of Economics 64(3): 162-175.

Ng, S. and Perron, P. (2001). Lag Length Selection and the Construction of Unit Root Tests with Good Size and Power. Econometrica 69: 1519-1554.

Piazzesi, M. (2010). Affine Term Structure Models in Yacine Ait-Sahalia and Lars Hansen, Handbook of Financial Econometrics: Elsevier Edited.

Rose, A. K. (1988). Is The Real Interest Rate Stable? Journal of Finance 43: 1095-1112.

Rudebusch, G. (1995). Federal Reserve Interest Rate Targeting, Rational Expectations and the Term Structure. Journal of Monetary Economics 35(2): 245-274.

South African Reserve Bank (SARB) Fact Sheets (2007). Available at https://www.resbank.co.za/AboutUs/Documents/Interest\%20rates\%20and\%20how\%20they\%20 work.pdf. Last accessed on 28/07/2015.

Schaling, E. Verhagen, W., and Eijffinger, S. (2009). The Term Structure of Interest Rates and Inflation Forecast Targeting. South African Journal of Economics 12 (2): 162-179.

Schwert, W. (1986). Test for Unit Roots: A Monte Carlo Investigation. Journal of Business and Economic Statistics 7: 147-159.

Shen, C. H., Chen, C. F., and Chen, L. H. (2007). An Empirical Study of the Asymmetric Cointegration Relationships among the Chinese Stock Markets. Applied Economics 39: 14331445.

Siklos, P., and Granger, C. W. J. (1997). Regime Sensitive Cointegration with an Application to Interest Rate Party. Macroeconomic Dynamics 3: 640-657.

Stock, J. H., and Watson, M. W. (1988). Variable Trends in Economic Time Series. Journal of Economic Perspectives. American Economic Association 2(3): 147-174. 
Stock, J. and Watson, M. (1989). New Indexes of Coincident and Leading Indicators. National Bureau of Economic Research, Macroeconomic Annual 4:351-394.

Sun, C. (2011). Price Dynamics in the Import Wooden Bed Market of the United States. Forestry Policy and Economics 13: 479-487.

Taylor, M. P. (1992). Modelling the Yield Curve. The Economic Journal 102: 524-537.

Taylor, M. P., Peel, D. A., and Sarno, L. (2001). Nonlinear Mean-Reversion in Real Exchange Rates: Towards a Solution to the Purchasing Power Parity Puzzles. International Economic Review 42: 1015-1042.

Tesfaselassie, M., Schaling, E., and Eijffinger, S. (2006). Learning about the Term Structure and Optimal Rules for Inflation Targeting, CEPR Discussion Paper, No. 5896, October.

The International Financial Statistics (2015). Available at http://elibrarydata.imf.org/FindDataReports.aspx?d=33061\&e=169393

Venter, J. C. and Pretorius, W. S. (2004). Note on the revision of composite leading and coincident business cycle indicators. Quarterly Bulletin. March.

Wallace, M. S., and Warner, J. T. (1993). The Fisher Effect and the Term Structure of Interest Rates: Tests of Cointegration. Review of Economics and Statistics 75: 320-324.

Yau, H-Y., and Nieh, C-C. (2009). Testing for Cointegration with Threshold Effect between Stock Prices and Exchange Rates in Japan and Taiwan. Japan and the World Economy 21: 292300 . 